\title{
Solar Concentrated Energy Supply to Water-Ammonia Absorption Refrigerators
}

\author{
Behnam Mostajeran Goortani, Sayyed Taher Kermani Alghorayshi \\ Renewable Energies Engineering Department, Faculty of Advanced Sciences and Technologies \\ University of Isfahan, Isfahan, Iran \\ b.mostajeran@ast.ui.ac.ir; taherkermani@ymail.com; b.mostajeran@ast.ui.ac.ir
}

\begin{abstract}
A gPROMS model for concentrated solar absorption chillers is developed. The advantages of a thermal heat storage system in terms of absorbing drastic solar energy change and storing the energy for working overnight and working during cloudy hours are assumed and calculated in a quantitative manner. The project is an ongoing project supported by Iran Office of Vice-presidency for Science and Technology and has broader objective of practical use of large scale linear Fresnel collectors for cooling applications. Consequently, some preliminary studies were performed. A novel dual axis Fresnel collector with overall dimensions of $12.70 \mathrm{~cm}$ by $2.30 \mathrm{~cm}$ and total mirrors area of $16.5 \mathrm{~m}^{2}$ is designed and fabricated. A model of receiver, a vacuum tube metal-glass of $20 \mathrm{~cm}$ diameter, is first designed and fabricated and tested. CFD modeling with Fluent was utilized to predict velocity and temperature profiles in non-continuous operation mode of the receiver. The profiles of velocity and temperature at receiver angles of $10,20,40$ and 50 degrees corresponding to the sun elevation angle variations during the year are determined. At the receiver angle of 10 degrees (corresponding to mid-summer), a maximum velocity of $4 \mathrm{~cm} / \mathrm{s}$ was obtained at the center. The location of this maximum velocity changes toward the wall by increasing the receiver angle.
\end{abstract}

Keywords: Concentrated solar heat, Absorption chiller, Linear Fresnel collector, CFD modeling

\section{Introduction}

Significant amount of consumed energy in the world is used for cooling applications. In warm climate areas with high solar irradiances, this energy consumption is very high. In Iran more than $60 \%$ of the electrical energy consumed, during warm months of the year, is used for cooling the building sector. Utilizing solar thermal energy is an efficient method to provide the energy need for cooling.

A standard solar system for cooling applications is assessed in [1]. Two water-ammonia absorption chillers with a COP of 0.6 , total cooling power of $24 \mathrm{~kW}$, and operating temperature of $450 \mathrm{~K}$ were chosen and four ice storages with a total volume of $1.200 \mathrm{~m}^{3}$ and a corresponding melting thermal capacity of $110 \mathrm{kWh}$ was applied to enable peak shifting. The feasibility of utilizing a solar powered absorption cycle subject to Abu Dhabi's (UAE) weather conditions is assessed in [2]. The solar air conditioner system had a specific collector area of $6 \mathrm{~m}^{2} / \mathrm{kWc}$ and a specific tank volume of 0.1 $\mathrm{m}^{3} / \mathrm{kWc}$.

With respect to the nature of sun thermal energy subject to 'vary with time' [3], particularly sun thermal energy, it is necessary to utilize and store the energy for night consumption. For this purpose, a solar absorption chiller is usually composed of three components: solar collector, thermal storage, and absorption cycle.

The Receivers of Fresnel collectors are mostly made of glass and are divided into single-tube and multi-tube types. In a study by Abbas et al. about multi-tube receivers, the highest thermal efficiency was obtained at 58\% [4]. If Multi-tube receivers are not vacuumed, convection heat lost become high due to radiation is not completely absorbed in the tubes and it is reflected in cavity [5]. Non-vacuum tubes have the most thermal losses. This is due to the fact that the absence of a vacuum makes it easy to convection heat transfer, which is the most and the worst factor in the thermal losses in receivers [5]. In another design by Pauletta, the flat-panel receiver was designed and built for the Fresnel collector built in CERN. Thanks to the large amount of vacuum left on this flat panel, it has a good thermal performance. At $200{ }^{\circ} \mathrm{C}$, it has $65 \%$ efficiency and, with an increase in temperature, reaches $60 \%$ at $400^{\circ} \mathrm{C}$. The disadvantages of this receiver can be a large area that results an increase in thermal radiation loss compared with the tubular receivers. 
There exist two important concerns in the utilization of solar heat for cooling applications: 1) knowledge of the parameters of solar cooling system and 2) practical experience with suitable solar thermal collector to provide the thermal energy need, particularly for the building sector. The objective of this study is in responding these two concerns. A homemade $20 \mathrm{~cm}$ diameter metal-glass vacuum receiver model was tested, as well, successfully in this study, because of the limitation in the diameter of the existing metal-vacuum tube receivers.

\section{Concentrated Solar Absorption Chiller}

An absorption cycle, used in many commercial refrigerators such as Sevrel-Electroloux, is schematically shown in Fig.1. The thermal energy of a circulating heat transfer fluid (i.e. salt melt) is received from the sun and sent to the generator of the absorption refrigerator. The absorption refrigerator consumes the thermal heat in the generator to provide cooling in the evaporator.

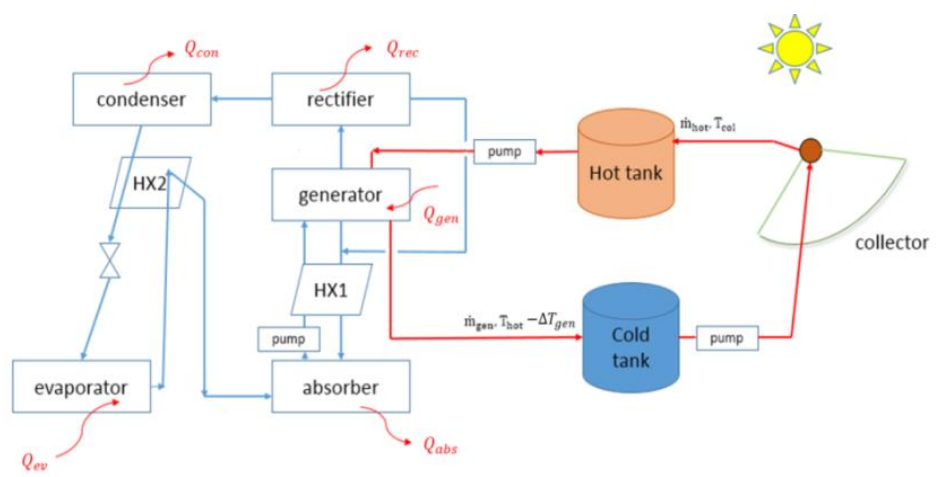

Fig. 1: A concentrated solar thermal absorption refrigerator.

\section{Modeling Solar Absorption Chiller}

The gPROMS software is an advanced modeling tool applied in modeling mass and energy balances of the equipment and processes under transient or steady state conditions. This software is mainly utilized in oil and gas research sector [7]. Together with Multiflash and material properties data banks, this software is equation-oriented and allows user to write appropriate equations and solve them in a simultaneous manner by assuming variable physical and thermodynamic properties of the materials. The equations applied in calculating these properties for the pure components and mixtures, in vapor and liquid phases, are all presented as functions of pressure, temperature, and components fractions.

Mass and energy balances are presented and solved in gPROMS, simultaneously. Physical and thermodynamic properties of the liquid and vapor phases are calculated through Multiflash which is physical and thermodynamic property calculation software. Different thermodynamic and physical property models are applied in this model in the vapor and liquid phases.

The model results indicate that without solar heat storage, at a collector area of $0.45 \mathrm{~m}^{2}$, by variations in solar irradiance from $300 \mathrm{~W} / \mathrm{m}^{2}$ to $1000 \mathrm{~W} / \mathrm{m}^{2}$, the generator duty and COP increase from $100 \mathrm{~W}$ to $250 \mathrm{~W}$ and from 0.07 to 0.32 , respectively. To assure the permanent operation of the refrigerator during the day and night with a thermal storage capacity for 12 hours and considering the heat losses thereof, a total capacity of $200 \mathrm{~kg}$ thermal storage medium (i.e. hot oil) and a collector surface area of $6.7 \mathrm{~m}^{2}$ is required.

The project is an ongoing project supported by Iran Office of Vice-presidency for Science and Technology (contract No. 11/65557) and has broader objective of practical use of large scale linear Fresnel collectors for cooling applications. Consequently, some preliminary studies were performed on the fabrication and practical application of these collectors. A novel, $16 \mathrm{~kW}$ dual axis linear Fresnel collector with a vacuum tube metal-glass receiver model was first fabricated. CFD modeling with Fluent was utilized to obtain velocity and temperature profiles in non-continuous operation mode of the receiver.

\section{Preliminary Tests with Novel Linear Fresnel Collector}

The collector is designed at the University of Isfahan and fabricated by Sharif Corp (Dolatabad, Isfahan, Iran). The system has a nominal capacity of $16 \mathrm{~kW}$ and equipped with a two dimensional sun tracking system. The collector consist 
of 45 mirrors (length=180 $\mathrm{cm}$, width $=20 \mathrm{~cm}$ ). The system has a modular structure, thus there is the possibility of increasing the number of mirrors; thus, solar concentration ratio on the receiver can be increased. All mirrors are installed on a principal frame of the collector and their vertical movement can be adjusted, Fig. 2. Sun elevation angle in Iran, Isfahan is 12 degrees at 12 o'clock on January 1st. In July, its highest value is 80 degrees, corresponding to 10 degrees vertical angle of the mirrors' frame.

The reported receivers in the literature are vacuum tube metal receivers of limited diameter or cavity receivers. To be able to use them in practice, multiple receivers should be applied, where their design is complicated. With the objective of reducing the complexity of design, a homemade $20 \mathrm{~cm}$ diameter metal-glass vacuum receiver model was tested successfully in this study. In order to know the practical limitations of fabricating and applying the real receiver, this model of receiver with smaller dimensions (length $=60 \mathrm{~cm}$, diameter $=20 \mathrm{~cm}$ ) is fabricated and tested. A $3 \mathrm{~kW}$ heating element for pre-heating salt was installed inside the receiver model. The salt is a mixture of sodium nitrate, potassium nitrate and sodium nitrite with a mass percentage of $7 \%, 49 \%$ and $44 \%$, respectively. Our laboratory observations with this salt indicated a melting temperature of around $145{ }^{\circ} \mathrm{C}$. Without vacuum, temperature up to $285{ }^{\circ} \mathrm{C}$ is reached and an average power of $1.4 \mathrm{~kW}$ is absorbed by the receiver.

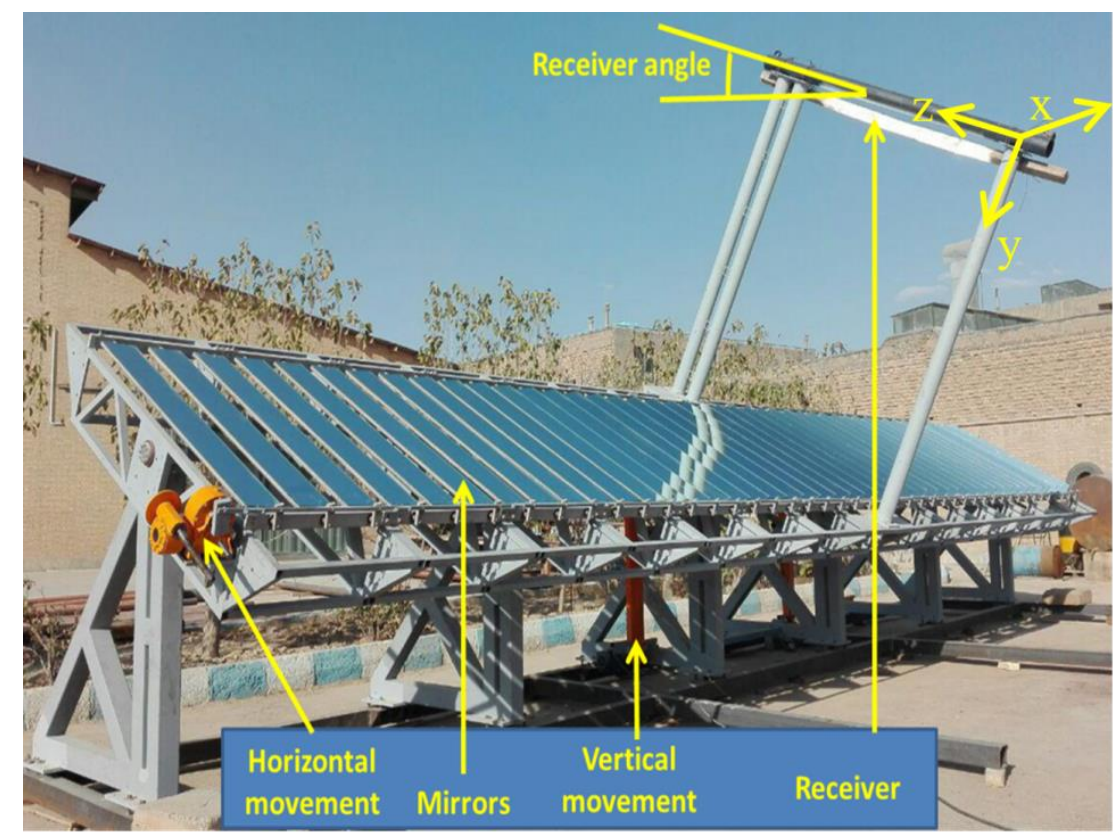

Fig. 2: Novel dual axis linear Fresnel collector designed and installed at University of Isfahan.

\section{Effect of Receiver Angle on Temperature and Velocity Profiles}

CFD modeling by ANSYS Fluent software was applied to find about the effect of receiver angle on the profiles of velocity and temperature. At receiver angles of 0,10, 20,30, 40, 50 degrees, and for 1100 second in transient mode, the profiles inside receiver are obtained. Parameters set in the software are tabulated in Table 1.

Table 1: Parameters set in CFD modelling.

\begin{tabular}{|l|l|}
\hline Parameter & Value \\
\hline Dimension & Cylinder of $20 \mathrm{~cm}$ diameter and $* 60 \mathrm{~cm}$ length \\
\hline Solver & Transient (time step 0.005-1 s) \\
\hline Viscous model & Transition SST $(4$ eqn) \\
\hline Energy model & On \\
\hline Boundary conditions & $30000 \mathrm{~W} / \mathrm{m}^{2}$ heat flux on wall \\
\hline
\end{tabular}




\subsection{Profiles of Velocity}

In the horizontal position of receiver (0 degree receiver angle according to Fig. 2), the fluid flows upward near the wall and it flows downward around the centre. The maximum velocity is $4 \mathrm{~cm} / \mathrm{s}$ at the middle of receiver. Velocity profiles, in the x-y plane (cross sectional area) at the middle of receiver, at 0, 10, 20, 40, and 50 degrees are shown in Figs. 3-a, 3-b, 3c, 3-d, and 3-e, respectively.

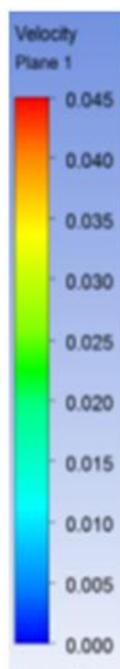

[m sk-1]

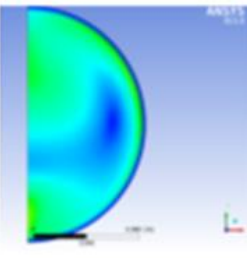

(a)

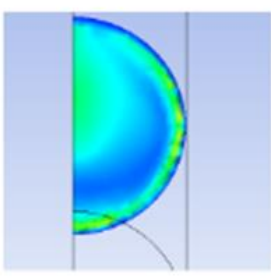

(d)

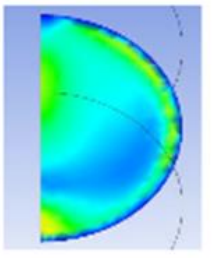

(b)

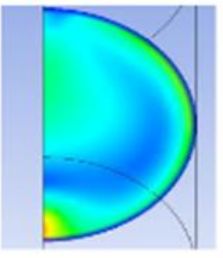

(c)

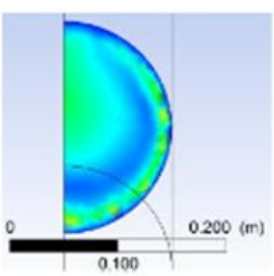

(e)

Fig. 3: Velocity profiles in x-y plane.

Velocity profiles, in the y-z plane (along the receiver axis of symmetry) are shown in Fig. 4. There exists a high velocity gradient near the wall. The width of this gradient is less at larger receiver angles, indicating that higher velocities by natural convection are created by an increase in receiver angle.
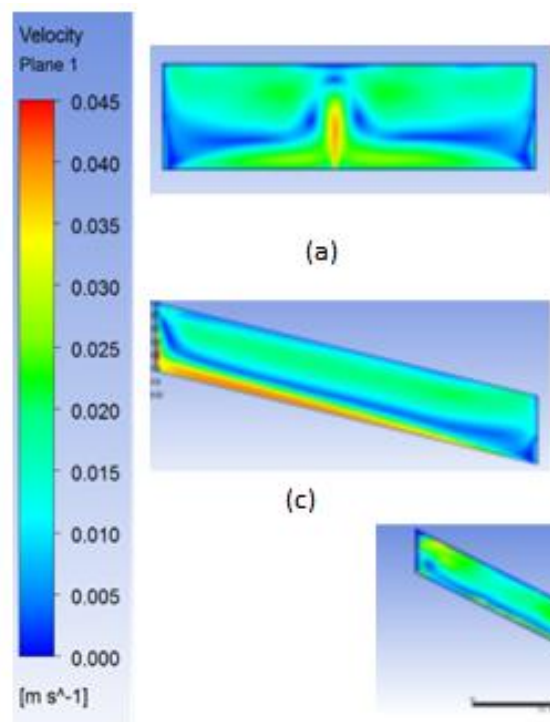

(c)

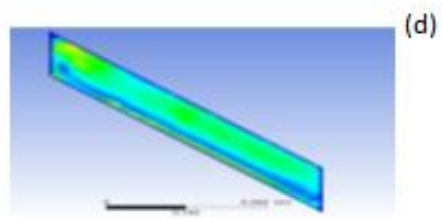

(e)

Fig. 4: Velocity profile in y-z plane. 


\subsection{Profiles of Temperature}

Temperature profiles, in the $x-y$ plane (cross sectional area) at the middle of receiver, at $0,10,40$, and 50 degrees are shown in Figs. 5-a, 5-b, 5-c, and 5-d, respectively. The exist a high temperature gradient near the wall. The width of this temperature gradient is more at larger receiver angles, indicating that mixing increases by an increase in receiver angle.

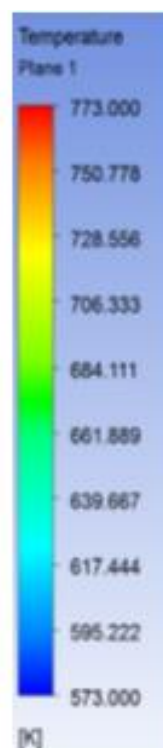

$\mathrm{kg}$

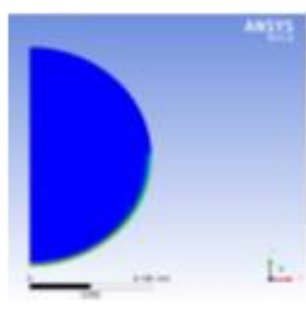

(a)

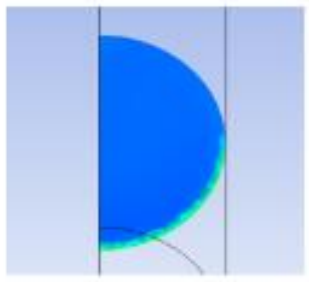

(c)

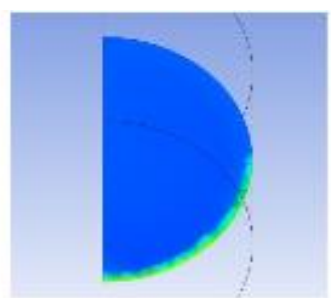

(b)

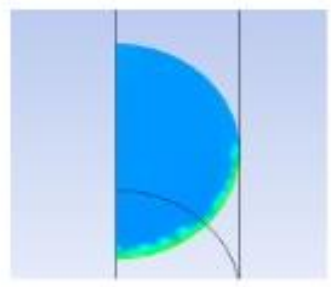

(d)

Fig. 5: Temperature profile in $x-y$ plane.

Temperature profiles, in the $\mathrm{y}-\mathrm{z}$ plane at the middle of receiver, at 0, 40, and 50 degrees are shown in Figs. 5-a, 5-b, and 5c, respectively.

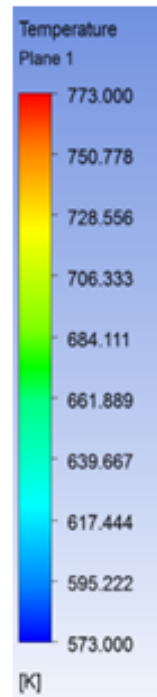

[K]

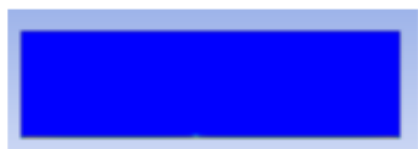

(a)

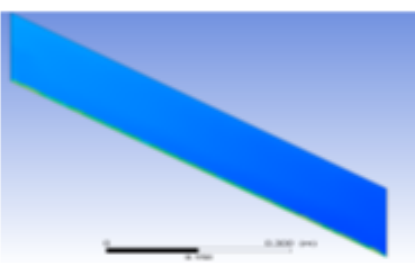

(b)

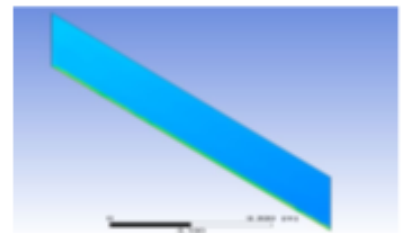

(c)

Fig. 6: Temperature profile in y-z plane.

\section{Conclusion}

A study is presented to increase our knowledge on the parameters of concentrated solar water-ammonia absorption chillers and to gain practical experience with a potentially suitable solar thermal collector, novel linear Fresnel, to provide 
the thermal energy need for the building sector. The collector is dual axis and has potential application in coupling with absorption chillers for home cooling applications. A homemade $20 \mathrm{~cm}$ diameter metal-glass vacuum receiver model was tested successfully in this study, because of the limitation in the diameter of the existing metal-vacuum tube receivers. Effect of receiver angle on the profiles of temperature and velocity is further assessed by CFD modeling. By an increase in receiver angle, from horizontal (in the summer) to 60 degrees in the winter, profiles of temperature and velocity change significantly.

\section{Acknowledgements}

The support received from Prof. Mojtaba Mostajaboddavati from University of Isfahan and prof. Aliakbar Alemrajabi from Isfahan University of Technology is acknowledged. The fund of this research is provided by Iran Office of Vicepresidency for Science and Technology, Office of Development of Renewable Energy Technologies. The authors thank the supports received from the dean of research at the University of Isfahan.

\section{References}

[1] L. B. Michael, W. Matthias, W. Christine, D. Jochen, M. Alexander, H. Andreas "Solar driven cold rooms for industrial cooling applications," Energy Procedia, vol. 30, pp. 904-911, 2012.

[2] A. Al-Alili, M. D. Islam, I. Kubo, Y. Hwang, R. Radermacher "Modeling of a solar powered absorption cycle for Abu Dhabi," Applied Energy, vol. 93 , pp. 160-167, 2012.

[3] B. Mostajeran Goortani, H. Heidari "Advanced modeling of CSP plants with sensible heat storage: instantaneous effects of solar irradiance," International Journal of Renewable Energy Research, 2017 (in press).

[4] R. Abbas, J. Muñoz "Steady-state thermal analysis of an innovative receiver for linear Fresnel reflectors," Appl. Energy., vol. 92, pp. 503-515, 2012.

[5] J. Facão, A. C. Oliveira "Numerical simulation of a trapezoidal cavity receiver for a linear Fresnel solar collector concentrator," Renew. Energy., vol. 36, pp. 90-96, 2011.

[6] A. Heimsath, F. Cuevas, A. Hofer, P. Nitz, W. J. Platzer "Linear Fresnel Collector receiver: Heat loss and temperatures," Energy Procedia, vol. 49, pp. 386-397, 2013.

[7] B. M. Goortani, A. Gaurav, A. Deshpande, F. T. T. Ng, G. L. Rempel "Production of isooctane from isobutene: energy integration and carbon dioxide abatement via catalytic distillation," Ind. \& Eng. Chem. Res., vol. 54 no. 14, pp. 3570-3581, 2015. 